\title{
André GounOT (dir.) Le sport en France de 1870 à 1940
}

Stadion, International Journal of the History of Sport, Académia Velag, Sankt Augustin, 2001, 265 p.

Jacques Gleyse

\section{OpenEdition}

Journals

Édition électronique

URL : http://journals.openedition.org/corpsetculture/983

DOI : $10.4000 /$ corpsetculture.983

ISSN : $1777-5337$

Éditeur

Association Corps et Culture

Édition imprimée

Date de publication : 1 janvier 2004

ISSN : 1268-5631

Référence électronique

Jacques Gleyse, «André Gounot (dir.) Le sport en France de 1870 à 1940 », Corps et culture [En ligne], Numéro 6/7 | 2004, mis en ligne le 31 mai 2007, consulté le 24 septembre 2020. URL : http:// journals.openedition.org/corpsetculture/983; DOI : https://doi.org/10.4000/corpsetculture.983

Ce document a été généré automatiquement le 24 septembre 2020.

(c) tous droits réservés 


\title{
André GOUNOT (dir.) Le sport en France de 1870 à 1940
}

\author{
Stadion, International Journal of the History of Sport, Académia Velag, \\ Sankt Augustin, 2001, 265 p.
}

Jacques Gleyse

1 C'est une très belle réalisation que propose André Gounod, Maître de conférences en STAPS, à l'Université de Strasbourg dans la revue trilingue, européenne STADION, concernant l'Histoire du sport en France entre 1870 et 1940. Il a réussi en effet le tour de force de réunir là une vingtaine d'auteurs français et étrangers, spécialistes du domaine, mais s'exprimant pour la plupart en langue française (deux articles sont en Allemand et deux en anglais) dans le but de proposer une production pour le moins originale, précise et documentée sur le sujet. Lorsque l'on fait la liste de ces auteurs; Jean-François Loudcher, Christian Vivier, Pierre Arnaud, Benoît Caritey, Jean-Paul Callède, Laurence Muñoz, Nicolas Kssis, Jérôme Bauchez, William Gasparini, Otto Schantz, Christopher Thompson, Jean-Michel Delaplace et Sylvain Villaret, JeanPhilippe Saint-Martin, Richard Holt, Yves Moralès, Serge Fauché, Michel Raspaud, Luc Robène, on comprend que c'est à un travail de qualité auquel nous sommes confrontés.

2 Après une préface, très riche, en langue anglaise d'André Gounod, le texte se divise en six grandes parties. La première est constituée d'éléments d'historiographie concernant les sports en France et notamment leur institutionnalisation. La deuxième partie s'intéresse au passage de l'initiative privée à l'intervention de l'Etat pour ce qui concerne les politiques sportives entre 1870 et 1940 . On passe dans cette partie des sociétés conscriptives et des athlètes de la IIIème République à l'invention des politiques publiques des sports (1919-1939) en passant par les sociétés agréées et les prémices d'une politique sportive (1908-1940). La troisième partie est consacrée aux mouvements sportifs et aux affinités idéologiques. Elle touche les domaines du sport catholique en France, du sport socialiste avant 1914, du sport travailliste (langue allemande) et des clubs sportifs strasbourgeois sous l'annexion allemande (1879-1914).

3 La quatrième partie s'intéresse davantage aux acteurs historiques et aux politiques éducatives, plus précisément aux pédagogies sportives. Là sont explorées les visions 
pédagogiques du Baron Pierre de Coubertin (langue allemande), les mystiques de " gauche » et de "droite » en pédagogie sportive sous la III ${ }^{e}$ République, le contrôle des masses au travers du contrôle de l'image du héros de la classe laborieuse dans la philosophie sociale d'Henri Desgrange et enfin, les succès de la méthode naturelle de Georges Hébert pour ce qui concerne le domaine de l'éducation avant 1914.

4 La cinquième partie touche aux influences des modèles anglais et scandinaves sur le sport et les gymnastiques au cours de la période étudiée. Trois textes sont présentés, l'un s'intéressant particulièrement aux influences suédistes, l'autre, en langue anglaise, à l'anglomanie et au renouveau national et le troisième aux influences étrangères sur le domaine particulier du ski.

5 La sixième et dernière partie est consacrée à l'idéologie sportive entre science et mythes nationaliste. Elle se centre sur trois visions : la première concerne les rapports entretenus entre sciences et idéologies dans le domaine vélocipédique, la deuxième touche à la conception française de l'himalaysme, la troisième s'intéresse à Henry de la Vaulx et à l'invention des sports aériens.

6 Suivent de nombreux comptes rendus de lecture forts stimulants.

7 Bref, on le voit, ce patchwork bigarré, argumenté et approfondi ne peut que devenir un ouvrage de référence dans le domaine de l'Histoire des pratiques corporelles au cours de la troisième République.

Il sera, en tout état de cause, indispensable aux étudiants d'agrégation externe d'EPS en ce qui concerne l'écrit I et, de ce fait, aux futurs étudiants en EPS, de l'Ecole Normale supérieure qui va être créée en Bretagne, dans les mois à venir. 